\title{
Theoretical and experimental investigations of double emulsion preparation by
}

\section{ultrasonication}

Behnam Khadem, Nida Sheibat-Othman ${ }^{*}$

University of Lyon, Université Claude Bernard Lyon 1, CNRS, LAGEPP UMR 5007, F-69100,

Villeurbanne, France

*Corresponding author : nida.othman@univ-Iyon1.fr

\section{Abstract}

Double emulsion preparation by ultrasonication is investigated in order to optimize the outer droplet size and the encapsulation efficiency. The effects of the sonication time, oil viscosity and the fractions of salt and primary emulsion are studied. A correlation is developed in order to predict the mean droplet diameter as a function of these parameters. The model is valid in the dissipation energy subrange. It accounts for the effects of salt within the surface force group, the oil viscosity within the viscous group, the primary fraction through energy damping and allows to predict the transitionary change in size with time. The properties of the outer droplets, such as the viscosity and density, take into account the presence of inner droplets. Based on this model, a leakage model is proposed where the rate increases proportionally with breakage, but continues at a constant rate once the size reaches equilibrium.

\section{Introduction}

Double emulsions, or emulsions of emulsions, consist of small droplets of one fluid suspended in larger droplets of another immiscible fluid ${ }^{1}$. They can be classified into two types: water-in- 
oil-in-water (W/O/W) or oil-in-water-in-oil (O/W/O) double emulsions. They are widely spread in food $^{2-4}, \operatorname{cosmetic}^{4,5}$, pharmaceutical ${ }^{4-6}$, chemical ${ }^{7,8}$, petrochemical ${ }^{7,8}$ and waste water treatment industries ${ }^{7,8}$. The final product quality in these applications is determined by the size of inner (i.e. micro-) and outer (i.e. macro-) droplets (also called globules) and the encapsulation efficiency of the internal phase ${ }^{2,4,9}$.

Matsumoto et al. $(1976)^{10}$ proposed the well-known two-step method to prepare double emulsions. In the first step, a primary emulsion is prepared where the internal phase is mixed with the intermediate phase under high energy to form small inner droplets. In the second step, the primary emulsion is dispersed into a continuous external phase to form the outer droplets $^{3,11}$. During this second preparation step, different phenomena may occur, including outer droplet breakage and coalescence, escape of inner droplets, swelling or shrinkage, and over-swelling breakdown ${ }^{4,9,12-15}$. These phenomena are governed by physical-chemical parameters and the energy dissipation by the emulsification device that need to be optimized in order to maximize the encapsulation rate and ensure a longer physical stability of the double emulsion.

Schuch et al. (2014) $)^{16}$ investigated the preparation of double emulsions in different devices and deduced that the encapsulation efficiency was proportional to the outer droplet size, independently of the type of device. Lindenstruth et al. (2004) $)^{11}$ proposed that the encapsulation rate was governed by the size ratio between inner and outer droplets, that should be reduced in order to increase the yield. They also indicated a reduction of the encapsulation efficiency during preparation due to the escape of inner droplets that accompanies the breakage of outer droplets, hereafter called leakage. For this reason, the 
mixing energy and time of the second step are generally lowered in order to increase the yield, which leads to big outer droplets compared to the inner droplets. Nevertheless, fine outer droplets may induce other advantages like preventing creaming, thus enhancing the stability during storage $\mathrm{e}^{3,17,18}$ or increasing the transparence of the final product ${ }^{19}$. Therefore, there is a compromise to be determined between droplet size and encapsulation rate ${ }^{16}$.

Emulsions, and so double emulsions, can be produced using different emulsification devices, like impellers, high speed rotor-stators, high pressure homogenizers, microfluidic devices, membranes, or ultrasonicators ${ }^{16,17,20}$. Among these techniques, ultrasonication allows producing very fine emulsions within a short emulsification time, and it constitutes an easy and clean process $^{21}$. Ultrasonic waves transmitted through a liquid induce acoustic cavitation, which consists of the nucleation, growth and collapse of gaseous bubbles in the fluid ${ }^{22-24}$. When applied on a two phase interface, the interfacial waves caused by the propagation of ultrasound erupt the dispersed phase into the continuous phase in the form of droplets. Then, the acoustic cavitation causes intense physical shearing within the continuous phase, which generates turbulent eddies and allows gradual breakage of the droplets ${ }^{20,25}$. During this process, part of the acoustic energy is degraded into heat under the effect of viscous friction ${ }^{20,22-25}$.

Ultrasonication has been widely used for the preparation of nanometric single emulsions $s^{19,26-29}$ and it represents a topic of growing interest for double emulsions, for instance for pharmaceuticals ${ }^{30}$ and food ${ }^{31}$. The process parameters affecting the yield and mixing efficiency, or droplet size, are the sonication time and energy level. While increasing their levels would allow for a better mixing and the production of smaller droplets, it may destroy the double emulsion leading to total leakage of the inner droplets ${ }^{32}$. Another disadvantage of increasing 
the sonication time or power is related to the associated increase in temperature and pressure which may cause the degradation of the encapsulated ingredient, the emulsifier or the organic phase $^{20}$. Therefore, there are optimal conditions to be determined. The encapsulation efficiency was reported to decrease when increasing the sonication time ${ }^{30,33}$. This observation was confirmed by Tang et al., who also found the addition of gelatin in the inner phase reduces droplet coalescence due to the formation of an interfacial rigid film, and investigated the effect of the concentration of surfactants ${ }^{34,35}$. The minimal power amplitude ensuring the production of cavitation was theoretically examined by Tal-Figiel $(2007)^{36}$. Leong et al. indicated that increasing the sonication power led to a decrease in the droplet size. The encapsulation efficiency was found to increase when decreasing the fraction of the internal water phase and when increasing the fraction of the primary emulsion; However the fraction of the primary emulsion had no effect on the outer droplet's size, except for extremely low, or extremely high sonication powers ${ }^{3}$. They also investigated other parameters like the fraction of surfactant ${ }^{37,38}$. For a better comprehension and optimization of the process, different modelling approaches were proposed in order to predict the encapsulation efficiency and the outer droplet size during the preparation of double emulsions in different devices. Okazaki et al. (1992) proposed a correlation to estimate the leakage rate in a stirred tank as a function of energy dissipation, viscosity and osmotic pressure over a specific salt concentration range. Concerning the mean droplet size, a number of correlations were proposed for single emulsions produced in stirred tanks ${ }^{40-43}$, which were then used for double emulsions ${ }^{44-47}$. For single emulsions preparation using sonication, the mean droplet diameter was predicted by semi-empirical correlations $^{19,36,48,49}$ or based on fundamental investigations, such as Nazarzadeh and Sajjadi 
$(2010)^{50}$ and Gupta et al. $(2016)^{51}$ who investigated the preparation in the dissipation subrange. These correlations will be investigated in this work and adapted for double emulsions. Indeed, some physical parameters of the emulsion change when the dispersed phase becomes itself an emulsion, i.e. during the second step of double emulsion preparation. A model is then developed to predict the release rate based on the breakage. The model needs to take into account the parameters that were found to affect the droplet size and the encapsulation efficiency in the literature review presented above.

The objective of this work is to investigate the effect of different operating conditions in ultrasonic emulsification on the yield and the outer droplet size and to propose correlations to estimate the leakage rate and outer droplet size as a function of the sonication time. W/O/W double emulsions are produced using ultrasonication in both steps. Different operating parameters were investigated, namely the sonication time of the second step, the oil viscosity, the internal fraction and the salt concentration.

\section{Experimental}

\subsection{Materials}

Different types of mineral oils were used to prepare the $\mathrm{W} / \mathrm{O} / \mathrm{W}$ double emulsions: white mineral oil (Fisher Scientific), fluid paraffin oil (Cooper), Marcol 82 (ExxonMobil) and Marcol 52 (ExxonMobil). The used emulsifiers were Span 80 (Alfa Aesar) as hydrophobic emulsifier and Tween 80 (Fisher Scientific) as hydrophilic emulsifier. Sodium Chloride was used as tracer. Millipore water with resistivity $\approx 18.2 \mathrm{~m} \Omega$.cm was used all over the work. 


\subsection{Double emulsion preparation}

Sonication was done using an ultrasonic processor (UP400S 400 watts, $24 \mathrm{kHz}$ ) equipped with a Sonotrode $\mathrm{H} 7$ (tip diameter $=7 \mathrm{~mm}$ ) manufactured by Hielscher Ultrasonics $\mathrm{GmbH}$.

W/O/W double emulsions were prepared using a two-step method, at room temperature, similarly to Leong et al. ${ }^{3}$. In the first step, the $\mathrm{NaCl}$ solution was dispersed in the oil phase consisting of oil in which Span 80 was dissolved. A total mass of $10 \mathrm{~g}$ was placed in a $20 \mathrm{ml}$ bottle and the Sonotrode tip was fixed at the interface of the aqueous and oil phases to help the interfacial waves to act immediately ${ }^{20}$. The sonication time of this first emulsification step was $30 \mathrm{~s}$ at amplitudes of $20 \%$. In the second step, part of the primary emulsion was dispersed in an external aqueous phase - consisting of water in which Tween 80 was dissolved - and emulsified with the same ultrasound device for 5-20 s, giving a total mass of $7.5 \mathrm{~g}$ of double emulsion. The calculated calorimetric $\operatorname{power}^{49,52}(P)$ of the first sonication step was $16 \mathrm{~W}$ and in the second step $P=9.4-11.76 \mathrm{~W}$. Table 1 shows the conditions and fractions of the used materials.

Table 1. Weight fractions and operating conditions

\begin{tabular}{|c|c|c|c|c|c|c|c|c|c|c|c|c|}
\hline & & & & prepa & ation ste| & & & Secc & nd prepara & tion ste & & \\
\hline & & & & ractior & (wt. \%) & & & tions (u & t. \%) & Opera & ing par & meters \\
\hline Set & Effect of & $\begin{array}{c}\mu_{\text {oil }} \\
\text { (mPa.s) }\end{array}$ & water & $\mathrm{NaCl}$ & Span 80 & Oil & Primary & water & Tween 80 & $t_{2}(\mathrm{~s})$ & $\Delta T(\mathrm{~K})$ & $P(\mathrm{~W})$ \\
\hline & & & & & & & & & & 5 & 1.5 & 9.4 \\
\hline 1 & $t$ & 15 & 10 & 005 & 095 & 80 & 10 & 89 & 1 & 10 & 3.5 & 11 \\
\hline & 2 & & & & & & & & & 15 & 5.5 & 11.5 \\
\hline & & & & & & & & & & 20 & 7.5 & 11.76 \\
\hline & & 6 & & & & & & & & & & \\
\hline 2 & $\boldsymbol{\mu}_{\mathrm{o}}$ & 22 & 10 & 0.05 & 9.95 & 80 & 10 & 89 & 1 & 10 & 3.5 & 11 \\
\hline & & 45 & & & & & & & & & & \\
\hline
\end{tabular}




\begin{tabular}{|c|c|c|c|c|c|c|c|c|c|c|c|c|}
\hline 3 & $\phi_{\mathrm{NaCl}}$ & 45 & 10 & \begin{tabular}{|r|}
0.025 \\
0.05 \\
0.1 \\
0.15 \\
\end{tabular} & 9.95 & 80 & 10 & 89 & 1 & 10 & 3.5 & 11 \\
\hline 4 & $\phi_{\text {Macro }}$ & 45 & 10 & 0.05 & 9.95 & 80 & $\begin{array}{l}10 \\
20 \\
30 \\
40 \\
\end{array}$ & $\begin{array}{l}89 \\
79 \\
69 \\
59 \\
\end{array}$ & 1 & 10 & 3.5 & 11 \\
\hline
\end{tabular}

${ }^{1}$ The total mass used in the first and second steps are $10 \mathrm{~g}$ and $7.5 \mathrm{~g}$ respectively.

\subsection{Droplet size measurements}

The inner droplets size distribution was measured right after the first preparation step by means of dynamic light scattering (Malvern Zetasizer Nano ZS ${ }^{\circledR}$ ). Before the measurement, the samples were diluted approximately 1:1000 (similar to ${ }^{3,9}$ ) in mineral oil. The analysis was performed twice for each sample, and every time three measurements were repeated, each of consisting of 11 runs. The Z-average was considered as the mean diameter of inner droplets. The outer droplets' size distribution was analyzed using laser diffraction (Malvern Mastersizer $3000^{\circledR}$ ). The refractive index of the outer droplets was considered to be that of oil (i.e. 1.467), which represents the main component of these droplets, especially close to the surface. Schmidts et al. $^{53}$ made the same assumption and validated the Mastersizer measurements of the outer droplets by optical microscope observations. The De broukere mean diameter, $d_{43}$, was considered for outer droplets.

\subsection{Conductivity measurements}

The released amount of $\mathrm{NaCl}$ was monitored by measuring the conductivity of the samples, taken after the second preparation step, using a CDM210 Conductivity Meter (MeterLab $\left.{ }^{\circledR}\right)$. The released amount was estimated based on a predetermined calibration curve. Two calibration methods were evaluated and found equivalent, either by dispersing different salt 
concentrations in pure water or by dispersing the salt in a single $\mathrm{O} / \mathrm{W}$ emulsion instead of water.

\subsection{Methods}

A preliminary study was conducted in order to determine the optimal sonication time and internal water fraction of the primary emulsion. First, the optimal sonication time of the primary emulsion was varied over the range of $30,60,90$ and $120 \mathrm{~s}$. The internal weight fraction at $20 \%$. The obtained mean inner droplet diameters (Z-average) were $d_{\mu}=540,425$, 394, $360 \mathrm{~nm}$. The emulsification time of the primary emulsion was fixed at $60 \mathrm{~s}$ since beyond this limit the inner droplet did not show an important decrease in their size and the emulsions were stable with $60 \mathrm{~s}$ emulsification. Second, the internal fraction was varied over the range of $10 \%, 20 \%, 30 \%$ and $40 \%$. It was found that different energy levels would be required in order to ensure uniform emulsification of the different fractions. In order to allow a straightforward comparison between the different experimental sets, the internal fraction was maintained at $10 \%$ with the energy level at $20 \%$ amplitude (i.e. $P=16 \mathrm{~W}$ ).

Thereafter, different key process parameters were investigated during the preparation of the double emulsions: including the sonication time of the second step, the primary emulsion fraction, the oil viscosity and the salt fraction (see Table 1). The internal and external droplet sizes were measured as well as the conductivity at the end of the emulsification. The mean

dissipation energy by ultrasound was determined using the following equation $\varepsilon=C_{\mathrm{P}} \frac{\mathrm{d} T}{\mathrm{~d} t}$, where $C_{\mathrm{P}}$ is the specific heat capacity of the liquid and $T$ its temperature ${ }^{3,49,54}$. 


\section{Modeling}

The outer droplet size and the encapsulation efficiency, or the escape of inner droplets during preparation, are the two main process variables that are interesting to model and predict during the emulsification by ultrasonication as a function of the different operating conditions that were found in the literature review to affect these variables.

\subsection{Mean droplet diameter}

In the turbulent regime, the Kolmogorov length scale of the smallest vortices is $\eta=\left(\frac{v^{3}}{\varepsilon}\right)^{1 / 4}$, where $v$ is the kinematic viscosity and $\varepsilon$ the energy dissipation ${ }^{55}$. At high Reynolds numbers, (i.e. a turbulence Reynolds number $R e_{L}>8630{ }^{56}$ ), the universal equilibrium range is divided into two subranges with regards to the eddy/vortex size $(\lambda)$ :

(1) The inertial subrange, $60 \eta \ll \lambda \ll L / 6$, in which the motion is dominated merely by the energy dissipation rate, thus the mean velocity fluctuation of an eddy of size $\lambda$ is given by $\overline{u_{\lambda}^{2}} \propto \varepsilon^{\frac{2}{3}} \lambda^{\frac{2}{3}}$, where $L$ is the scale of largest vortices;

(2) The dissipation or viscous subrange, $\eta \ll \lambda \ll 60 \eta$, where the motion is dominated by both the energy dissipation rate and the kinematic viscosity, thus the velocity is given by $\overline{u_{\lambda}^{2}} \propto \frac{\varepsilon \lambda^{2}}{v}$.

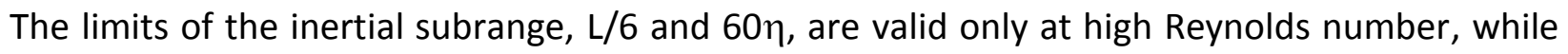
for moderate Reynolds they can reach $L / 2$ and $15 \eta{ }^{57,58}$. In this study, the outer droplet mean diameters are in the range of 10 to $60 \mu \mathrm{m}$, so below the limit between the inertial and viscous subranges (70-280 $\mu \mathrm{m}$ assuming $15 \eta-60 \eta)$. The main correlations proposed to estimate the droplet size in this subrange (i.e. dissipation) are given in Table 2. They will be modified to 
account for the properties of the different phases (i.e. fractions, viscosities), in analogy with the methodologies developed for the inertial subrange, shown in the same table. The correlations used for simple emulsions were also used in double emulsions, with some adaptations, mainly the effect of internal phase fraction ${ }^{59}$ and adding a swelling factor ${ }^{47}$ (Table 3 ). The equations proposed in the present work for double emulsions appear in the same table, and they will be developed in the following section.

Table 2. Mean diameter correlations for single emulsions, at equilibrium, under turbulent conditions

\begin{tabular}{|c|c|c|}
\hline Mean (or maximum) diameter correlation & Range & Ref. \\
\hline $\begin{array}{l}d \propto \varepsilon^{-\frac{2}{5}}\left(\frac{\sigma}{\rho_{\mathrm{c}}}\right)^{\frac{3}{5}} \\
\text { Or, } d / D_{\mathrm{I}} \propto W e^{-\frac{3}{5}}, \text { with } W e=\frac{\rho_{\mathrm{c}} \overline{u_{d}^{2}} d}{\sigma}, \overline{u_{d}^{2}} \approx \overline{u_{\lambda}^{2}} \text { (with } D_{\mathrm{I}} \text { the impeller diameter) }\end{array}$ & \multirow{4}{*}{$\begin{array}{l}\text { Inertial } \\
\overline{u_{\lambda}^{2}} \propto \varepsilon^{\frac{2}{3}} \lambda^{\frac{2}{3}}\end{array}$} & $\begin{array}{l}\text { Kolmogorov } \\
\text { Hinze }^{40}\end{array}$ \\
\hline $\begin{array}{l}\text { To account for the dispersed phase fraction, } \phi: \\
d / D_{\mathrm{I}} \propto(1+a \phi) W e^{-\frac{3}{5}} \\
\text { With } a=3.75 \text { for Calderbank (1958). Other values of } a \text { are available }{ }^{42,61,62} \text {. }\end{array}$ & & Calderbank $^{63}$ \\
\hline $\begin{array}{l}\text { To account for the dispersed phase viscosity, } \mu_{d} \text { : } \\
d \propto \varepsilon^{-\frac{2}{5}}\left(\frac{\sigma+\mu_{\mathrm{d}} \overline{u_{d}} / 4}{\rho_{\mathrm{c}}}\right)^{\frac{3}{5}}\end{array}$ & & Davies ${ }^{64}$ \\
\hline $\begin{array}{l}\text { To account for the viscosity ratio (with } \mathrm{D} \text { the static mixer diameter): } \\
d / D \propto W_{e}^{-\frac{3}{4}}\left(\frac{\mu_{\mathrm{d}}}{\mu_{\mathrm{c}}}\right)^{0.18}\end{array}$ & & Chen \& Libby ${ }^{65}$ \\
\hline$\frac{\mu_{\mathrm{c}} d}{\sigma} \frac{\partial \overline{u_{\lambda}}}{d \lambda}=\underbrace{\mathrm{f}\left(\frac{\mu_{\mathrm{d}}}{\mu_{\mathrm{c}}}\right)}_{\text {or } C a_{\text {crit }}}$ which gives $d \propto \sigma\left(\varepsilon \rho_{\mathrm{c}} \mu_{\mathrm{c}}\right)^{-\frac{1}{2}} C a_{\text {crit }}$ & \multirow{2}{*}{$\begin{array}{l}\text { Dissipation } \\
\overline{u_{\lambda}^{2}} \propto \frac{\varepsilon \lambda^{2}}{v}\end{array}$} & $\begin{array}{l}\text { Taylor }^{66,67} \\
\text { Shinnar }\end{array}$ \\
\hline$d \propto \rho_{\mathrm{d}}^{-\frac{1}{6}}\left(\varepsilon \rho_{\mathrm{c}} \mu_{\mathrm{c}}\right)^{-\frac{5}{12}} \sigma^{\frac{2}{3}} \mu_{\mathrm{d}}^{\frac{1}{3}}$ & & Gupta et al. ${ }^{51}$ \\
\hline
\end{tabular}

Table 3. Mean outer droplet diameter correlations in double emulsions

\begin{tabular}{|l|l|l|}
\hline$d / D_{\mathrm{I}} \propto\left(1+2 \phi_{\mu}\right)^{1.2}\left(1+2 \phi_{\mathrm{M}}\right)^{1.2} W e^{-0.6}\left(1+4.08 N_{\mathrm{vi}}\right)^{\frac{3}{5}}$ & Inertial & Sharma et al. ${ }^{59}$ \\
With $N_{\mathrm{vi}}=\left(\frac{\rho_{\mathrm{c}}}{\rho_{\mathrm{d}}}\right)^{1 / 2} \frac{\mu_{\mathrm{d}} \varepsilon^{-1 / 3} d^{1 / 3}}{\sigma}\left(1+2 \phi_{\mu}\right)^{-1}\left(1+2 \phi_{\mathrm{M}}\right)^{-1}$ & & \\
\hline
\end{tabular}




\begin{tabular}{|l|c|c|}
\hline$d / D_{\mathrm{I}} \propto W e^{-0.6} \phi_{\mathrm{M}}^{0.136}\left(\frac{\mu_{\mathrm{M}}}{\mu_{\mathrm{c}}}\right)^{0.11}\left(1+F^{\mathrm{SW}}\right)^{\frac{1}{3}}$ & & Gallego-Lizon \& \\
With $F^{\mathrm{SW}}=\frac{\mathrm{d}^{3}-\left(d^{0}\right)^{3}}{\left(d^{0}\right)^{3}}$ & Pérez de Ortiz $^{47}$ \\
\hline$d=K_{1}\left(\varepsilon \rho_{\mathrm{c}} \mu_{\mathrm{c}}\right)^{-\frac{1}{2}}\left(\frac{\mu_{\mathrm{M}}}{\mu_{\mathrm{c}}}\right)^{\beta}\left(1+2.5 \phi_{\mathrm{M}}\right)^{\frac{3}{2}}\left(\sigma_{\mathrm{M}}+K_{2} \phi_{\mu} C_{\text {salt }} R T d\right)\left(1+K_{3} \mathrm{e}^{-K_{4} t}\right)$ & Dissipation & This work \\
\cline { 1 - 2 }$C_{1}\left(\varepsilon \rho_{\mathrm{c}} \mu_{\mathrm{c}}\right)^{-\frac{5}{12}}\left(\frac{\mu_{\mathrm{M}}}{\mu_{\mathrm{c}}}\right)^{\beta-\frac{1}{3}}\left(1+2.5 \phi_{\mathrm{M}}\right)^{\frac{5}{4}}\left(\sigma_{\mathrm{M}}+C_{2} \phi_{\mu} C_{\mathrm{salt}} R T d\right)^{\frac{2}{3}}\left(1+K_{3} \mathrm{e}^{-K_{4} t}\right) \rho_{\mathrm{M}}^{-\frac{1}{6}} \mu_{\mathrm{M}}^{\frac{1}{3}}$ & This work \\
\hline
\end{tabular}

\section{Effect of the dispersed phase viscosity}

Taylor basis. Based on Taylor's theory of droplet deformation, there exists a critical generalized Weber group, $N_{\mathrm{We}}=\frac{\tau d}{\sigma}$, below which breakup does not occur, where $d$ is the droplet diameter, $\sigma$ the interfacial tension and $\tau$ the external force per unit area (i.e. the stress) acting on the surface of the droplet ${ }^{40}$. In the inertial subrange, $\tau$ represents the dynamic pressure $\tau=\rho_{\mathrm{c}} \overline{u_{\lambda}^{2}}$, from which the original Webber number can be obtained, $N_{\mathrm{We}}=W e=\frac{\rho_{\mathrm{c}} \overline{u_{d}^{2}} d}{\sigma}$, thus allowing to derive the Kolmogorov droplet size correlation for the inertial subrange (Table 2$)^{40}$. For the viscous subrange, which is of interest here, $\tau$ is a viscous stress $\tau=\mu_{\mathrm{c}} \frac{\partial \overline{u_{\lambda}}}{\partial \lambda}$, which gives the Capillary number ${ }^{66,67}, N_{\mathrm{We}}=C a=\frac{\mu_{\mathrm{c}} d}{\sigma} \frac{\partial u_{\lambda}}{\partial \lambda}$ (below which the droplets will not break). By applying the Kolmogorov velocity of the dissipation subrange into this equation, the following correlation can be obtained for the maximum droplet size at equilibrium ${ }^{40,68,69}: d_{\max } \propto$ $\sigma\left(\varepsilon \rho_{\mathrm{c}} \mu_{\mathrm{c}}\right)^{-\frac{1}{2}} C a_{\text {crit. }}$. The critical Capillary number can be described as a function of the viscosity ratio $^{70,71}$, i.e. $C a_{\text {crit }} \propto\left(\frac{\mu_{\mathrm{d}}}{\mu_{\mathrm{c}}}\right)^{\beta}$, where $\beta$ is a constant, which gives:

$d_{\max } \propto \sigma\left(\varepsilon \rho_{\mathrm{c}} \mu_{\mathrm{c}}\right)^{-\frac{1}{2}}\left(\frac{\mu_{\mathrm{d}}}{\mu_{\mathrm{c}}}\right)^{\beta}$ 
Where $\rho$ and $\mu$ are respectively the density and viscosity, and the subscripts $\mathrm{d}$ and $\mathrm{c}$ are indicators of the dispersed and continuous phases respectively. The curve of $C a_{\text {crit }}$ against the viscosity ratio $\frac{\mu_{\mathrm{d}}}{\mu_{\mathrm{c}}}$ is known to first decrease with this ratio up to $\frac{\mu_{\mathrm{d}}}{\mu_{\mathrm{c}}} \approx 1$ (i.e. $\beta$ is negative) and then $C a_{\text {crit }}$ increases with the viscosity ratio (i.e $\beta$ becomes positive), approximately when

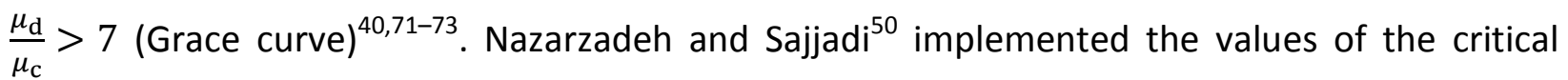
Capillary of Bentley and Leal $(1986)^{73}$ and fitted equation 1 in ultrasound emulsification operating in the viscous subrange, in which they observed a decrease then an increase in the mean droplet size with the viscosity ratio.

Hinze basis. Hinze $(1955)^{40}$ suggested that besides the generalized Weber group, the viscosity group that accounts for the viscosity of the droplet (i.e. the Ohnesorge number $O h=\frac{\mu_{\mathrm{d}}}{\sqrt{\rho_{\mathrm{d}} \sigma d}}$ ) also controls the droplet deformation. Following this suggestion, the Critical capillary is defined as $C a_{\text {crit }}=C(1+f(O h))$. Based on this, Gupta at al. $(2016)^{51}$ developed a correlation for the dissipation subrange with $C$ as a constant. However, in the suggestion of Hinze ${ }^{40}, C$ is function of the viscosity ratio $\frac{\mu_{\mathrm{d}}}{\mu_{\mathrm{c}}}$. In this case, the following correlation can be proposed:

$d_{\max } \propto \sigma^{\frac{2}{3}}\left(\varepsilon \rho_{\mathrm{c}} \mu_{\mathrm{c}}\right)^{-\frac{5}{12}}\left(\frac{\mu_{\mathrm{d}}}{\mu_{\mathrm{c}}}\right)^{\beta_{2}} \rho_{\mathrm{d}}^{-\frac{1}{6}} \mu_{\mathrm{d}}^{\frac{1}{3}}$

This correlation is valid for large Oh values, where the high viscous stresses inside the droplet necessitate higher inertial stress to break it.

Equations 1 and 2 will constitute the two main model basis, in which other properties of the double emulsions will be incorporated. In order to have a comparable effect of the viscosity of the dispersed phase in both models, we assume $\beta_{2}=\beta-\frac{1}{3}$ (as equation 2 contains a separate term $\mu_{\mathrm{d}}^{1 / 3}$ ). However, the power of the viscosity ratio will still be different in the two models. 
Effect of the dispersed phase fraction (damping effect)

Calderbank (1958) ${ }^{63}$ and Brown and Pitt $(1970)^{41}$ included the damping effect of the dispersed phase volume fraction $(\phi)$ on energy dissipation, $d^{\phi} \propto d^{0}(1+a \phi)$, with $a$ equal to 3.75 and 3.14 respectively. Based on series expansion, Doulah $(1975)^{61}$ estimated $a=3$ for the inertial subrange. By analogy, we can make the same development for the dissipation subrange. Based on the Kolmogorov length scale, the ratio of energy dissipation between the damped and nondamped system is $\frac{\varepsilon_{0}}{\varepsilon_{\phi}}=\left(\frac{v_{\phi}}{v_{0}}\right)^{3}$. By approximating the viscosity ratio using Einstein's equation, $\mu_{\phi}=\mu_{0}\left(1+\frac{5}{2} \phi\right)$, one obtains $\mathrm{d}^{\phi} \propto d^{0}(1+2.5 \phi)^{q}$ with $q=3 \times(-p)$, where $p$ is the power of $\varepsilon$ in the correlation of $d^{0}$. Doulah ${ }^{61}$ used $p=0.4$ in the inertial subrange. In the dissipation subrange, one should use $q=3 / 2$ and $5 / 4$ for equations 1 and 2 , respectively.

Effect of time, transitionary state

The available droplet size correlations are usually valid for stationary state, thus giving the equilibrium droplet size. For continuous emulsifications, it was suggested that the droplet diameter depends on the residence time, for instance $d \propto \tau^{-0.3}$ (Koglin, 1981) $)^{74}$, or $d \propto E_{\mathrm{v}}^{-b}$ with $E_{\mathrm{v}}=\varepsilon \tau$ being the energy density and $b \sim 0.4$ for turbulent breakage (Karbstein and Schubert ${ }^{48}$ ). In order to predict the evolution of the droplet size with time in the present system, the following correlation is proposed:

$d=d_{\mathrm{eq}}\left(1+K_{3} \mathrm{e}^{-K_{4} t}\right)$

Where $K_{4}$ is the breakage frequency and $d_{\text {eq }}$ is the equilibrium diameter that can be obtained from the stationary correlations, for instance using equations 1 and 2 . When $t \rightarrow \infty$, $\mathrm{e}^{-K_{4} t} \rightarrow 0$, which allows to get the stationary value, $d_{\mathrm{eq}}$. 


\section{Adaptations to double emulsions}

In double emulsions the dispersed phase is itself an emulsion, which requires specific correlations to calculate the outer droplets viscosity $\left(\mu_{\mathrm{M}}\right)$ and density $\left(\rho_{\mathrm{M}}\right)$. Moreover, the presence of salt may lead to swelling of the outer droplets, thus affecting their size and the escape rate. The properties of the inner (micro-) and outer (macro-) phases/droplets are distinguished and indicated with the indices $\mu$ and M respectively.

Viscosity and density. The apparent viscosity and density of a liquid-liquid dispersion (i.e. outer droplets here) can be obtained by the models of Vermeulen $(1955)^{75}$ and Miller and Mann $(1944)^{76}$ respectively:

$\mu_{\mathrm{M}}=\frac{\mu_{\mathrm{c}}}{1-\phi}\left(1+1.5 \phi \frac{\mu_{\mathrm{d}}}{\mu_{\mathrm{d}}+\mu_{\mathrm{c}}}\right)$

$\rho_{\mathrm{M}}=\phi \rho_{\mathrm{d}}+(1-\phi) \rho_{\mathrm{c}}$

The subscripts $d$ and $c$ refer to the dispersed (i.e. internal water) and continuous (i.e. oil) phases respectively.

Effect of salt. The concentration difference of salt between the internal and external phases creates a force on the surface of inner and outer droplets (i.e. osmotic pressure). The work required to strain a droplet containing other droplets is thus modified compared to the work required to strain a pure droplet ${ }^{77}$. This force can be added into the surface force group, and therefore the balance between the Laplace and osmotic pressures gives ${ }^{4,78,79}$ :

$\Delta P=\frac{4 \sigma}{d}-\sigma_{\text {reflx }} i C_{\text {salt }} R T$

Where $C_{\text {salt }}$ is the salt concentration in the inner droplets, $R$ the ideal gas constant, $T$ the temperature, $i$ the van't Hoff factor and $\sigma_{\text {reflx }}$ is the reflection coefficient of the membrane. Assuming the surface of the inner droplet to play the role of a membrane during release, it may 
be considered that $\sigma_{\mu} \propto d_{\mu} \sigma_{\text {reflx }} i C_{\text {salt }} R T$. Thus, the effective surface tension can be calculated by:

$\sigma_{\mathrm{M}, \mathrm{eff}}=\sigma_{\mathrm{M}}+K_{2} \phi_{\mu} C_{s \mathrm{alt}} R T d_{\mathrm{M}}$

Where $K_{2}$ is a parameter regrouping the different unknown constants (i.e. $\sigma_{\text {reflx }}$ and $i$ ) or deviations from an ideal behavior, and $\sigma_{\mathrm{M}}$ is the surface tension of the outer droplets having no salt (in this work considered as the oil-water surface tension, i.e. with $\phi_{\mu}=0$ ).

Complete droplet size correlation for double emulsions in ultrasonication

The different properties of the double emulsion discussed above were included into equations 1 and 2, which gives, based on the Taylor approach (eq. 1):

$d=K_{1}\left(\varepsilon \rho_{\mathrm{c}} \mu_{\mathrm{c}}\right)^{-\frac{1}{2}}\left(\frac{\mu_{\mathrm{M}}}{\mu_{\mathrm{c}}}\right)^{\beta}\left(1+2.5 \phi_{\mathrm{M}}\right)^{\frac{3}{2}}\left(\sigma_{\mathrm{M}}+K_{2} \phi_{\mu} C_{\text {salt }} R T d\right)\left(1+K_{3} \mathrm{e}^{-K_{4} t}\right)$

And by incorporating the Hinze suggestion into Taylor's approach, through Gupta development (eq. 2), the correlation becomes:

$d=C_{1}\left(\varepsilon \rho_{\mathrm{c}} \mu_{\mathrm{c}}\right)^{-\frac{5}{12}}\left(\frac{\mu_{\mathrm{M}}}{\mu_{\mathrm{c}}}\right)^{\beta-\frac{1}{3}}\left(1+2.5 \phi_{\mathrm{M}}\right)^{\frac{5}{4}}\left(\sigma_{\mathrm{M}}+C_{2} \phi_{\mu} C_{\mathrm{salt}} R T d\right)^{\frac{2}{3}}\left(1+K_{3} \mathrm{e}^{-K_{4} t}\right) \rho_{\mathrm{M}}^{-\frac{1}{6}} \mu_{\mathrm{M}}^{\frac{1}{3}}$

Where $K_{1}, K_{2}, K_{3}, K_{4}, C_{1}, C_{2}$ and $\beta$ are constants to be determined by fitting to the experimental data. The breakage frequency $K_{4}$ and the pre-exponential factor $K_{3}$ should have the same values in both models. The main differences between these correlations mainly lay in the powers of different terms.

\subsection{Leakage}

During the preparation by ultrasound, molecular diffusion of salt can be neglected due to the low solubility of the used salt in the oil phase and the short preparation time. Similarly, the escape of the inner droplets by diffusion is slow and can be neglected during preparation. 
Therefore, the main phenomena responsible for the release is inner droplets leakage, which is defined as the escape of inner droplets joining the breakage of outer droplets. The leakage rate can thus be correlated to the breakage rate, i.e. equations 8 and 9 .

The leakage rate is also proportional to the concentration of encapsulated salt. The concentration of salt in the outer droplets, $C_{\text {salt }}$, can be obtained from the following balance (here the release is measured by conductivity) ${ }^{39}$ :

$\frac{d C_{\text {salt }}}{d t}=-K_{\mathrm{L}} C_{\text {salt }}$

The leakage constant is suggested to be correlated to the droplet diameter $d$ (determined from equations 8 or 9) as follows:

$K_{\mathrm{L}}=\frac{K_{\mathrm{L} 0}}{d}$

Where $\mathrm{K}_{\mathrm{L} 0}$ is a tuning parameter. By this way, the leakage rate is related to the same phenomena governing breakage. Moreover, when the droplet size reaches equilibrium between breakage and coalescence, the leakage continues at a constant rate until emptying the outer droplets from the inner droplets. The encapsulation efficiency fraction, therefore, can be obtained by $E E(\%)=\frac{C_{\text {salt }}(t)}{C_{\text {salt }}(t=0)} \times 100=\exp \left(-K_{\mathrm{L}} t\right) \times 100$.

\section{Results and discussions}

The De Broukere mean diameter, $d_{43}$, was considered in fitting equations 8 and 9 . However, any other mean diameter can be used if preferred in some applications ${ }^{80,81}$. The unknown constants in equations 8,9 and 11 , were identified using a least square minimization in MatLab ${ }^{\circledR}$ environment (Table 4). It was found that both correlations 8 and 9 give similar curves in general (but with different constant values). Therefore, only the results of equation 8 are shown in the 
following figures, except for the case with fractions of salt higher than $0.21 \%$, where a deviation is observed.

Table 4. Constants of the mean droplet diameter and leakage correlations

\begin{tabular}{|c|c|c|c|c|c|c|c|}
\hline \multicolumn{7}{|c|}{ Constants of the mean diameter correlations } & Leakage \\
\hline \multicolumn{2}{|c|}{ Model 1 (Eq. 8) } & \multicolumn{2}{|c|}{ Model 2 (Eq. 9) } & \multicolumn{3}{c|}{ Both models } & Eq. 11 \\
\hline$K_{1}$ & $K_{2}$ & $C_{1}$ & $C_{2}$ & $\beta$ & $K_{3}$ & $K_{4}$ & $K_{\mathrm{L} 0}$ \\
\hline 0.0034 & 0.0095 & 0.0116 & 0.018 & 0.116 & 12.18 & $0.0864 \mathrm{~s}^{-1}$ & $2.8 \times 10^{-7}$ \\
\hline
\end{tabular}

\subsection{Sonication time of the second step}

The sonication time of the second step was varied over the range $5,10,15$, and $20 \mathrm{~s}$, and its effect on the droplet size and leakage was investigated (Set 1, Table 1). The primary emulsion was prepared with 60 s of sonication and $20 \%$ energy amplitude (16 W). The size distribution of the internal emulsion is presented in Figure $1 \mathrm{~A}$ giving a mean diameter of $425 \mathrm{~nm}$. This primary emulsion was stable over several hours, thus giving safely enough time for the preparation of the double emulsion.

Figures $1 \mathrm{~B}$ and $1 \mathrm{C}$ show the outer droplet size distribution and the mean diameter respectively. It can be seen that increasing the sonication time leads to the production of smaller outer droplets, until reaching an equilibrium between breakage and coalescence approximately after $15 \mathrm{~s}$ where further sonication a negligible effect. The encapsulation rate (Figure 1D) indicates that increasing the second step emulsification time leads to a higher leakage and thus to a lower yield. Indeed, in each breakage event, a number of inner droplets can leak out to the outer droplets due to the generated surface and the kinetic energy gained by the outer droplets. This confirms the fact that leakage is directly correlated to breakage. Consequently, 
bigger outer emulsions are recommended as they ensure a higher encapsulation efficiency, as far as these double emulsions are physically stable during storage and induce the final desired properties (e.g. transparence).

The models of the mean droplet diameter (equation 8) and the yield (equations 10-11) are shown on the same figures. The part of the mean diameter correlation that accounts for the sonication (emulsification) time of the second step is: $1+K_{3} \mathrm{e}^{-K_{4} t}$. It can be seen that the proposed correlations allow a good prediction of the tendencies as well as the final steady state of the outer droplet size. Note that even after reaching the equilibrium droplet size, the escape of inner droplet continues. Indeed, at equilibrium the breakage rate equals the coalescence rate, but breakage events persist, thus leading to inner droplet escape. In the next sections, the second emulsions will be prepared in $10 \mathrm{~s}$, which provides a good compromise between outer droplet size and encapsulation rate (around $80 \%$ ).

It is to be noted that the sonication causes an increase in the temperature that may affect the viscosity of the different phases and their interfacial properties ${ }^{20}$ or may lead to degradation of some materials, such as proteins or surfactants ${ }^{17}$. In this first set of experiments, the temperature increased from $23{ }^{\circ} \mathrm{C}$ to $30.5^{\circ} \mathrm{C}$ when the sonication time was the highest (20 s). However, the increase of $7.5^{\circ} \mathrm{C}$ was found to have a negligible effect on the viscosity. Indeed, the viscosity-temperature correlation of Stanciu (2012)82 was used and its parameters were identified for mineral oil, giving: $\mu=0.0018+8.22 \times 10^{4} \exp (-T / 20.47)$. Using this correlation, the viscosities were predicted to be: $45 \mathrm{mPa} s$ at $23^{\circ} \mathrm{C}, 42 \mathrm{mPa} \mathrm{s}$ at $24.5^{\circ} \mathrm{C}$, $34.8 \mathrm{mPa}$ s at $28.5^{\circ} \mathrm{C}$, and $31.7 \mathrm{mPa} \mathrm{s}$ at $30.5^{\circ} \mathrm{C}$. When implementing this viscosity change in the proposed models (equations 8 and 9), only a slight effect could be perceived on the final 
size and the leakage fraction. As mentioned above, in the following sets of experiments, the emulsification time is fixed at $10 \mathrm{~s}$, therefore, the increase in temperature is of $3.5^{\circ} \mathrm{C}$, which makes the change in viscosity negligible. Therefore, the viscosity of the oil at room temperature can reasonably be considered in both models, and any change due to the increase in temperature can be neglected. Nevertheless, in order to prevent any undesired side effects in case of big thermal increase, a cooling jacketed system may help to maintain the temperature constant during emulsification by sonication 17.
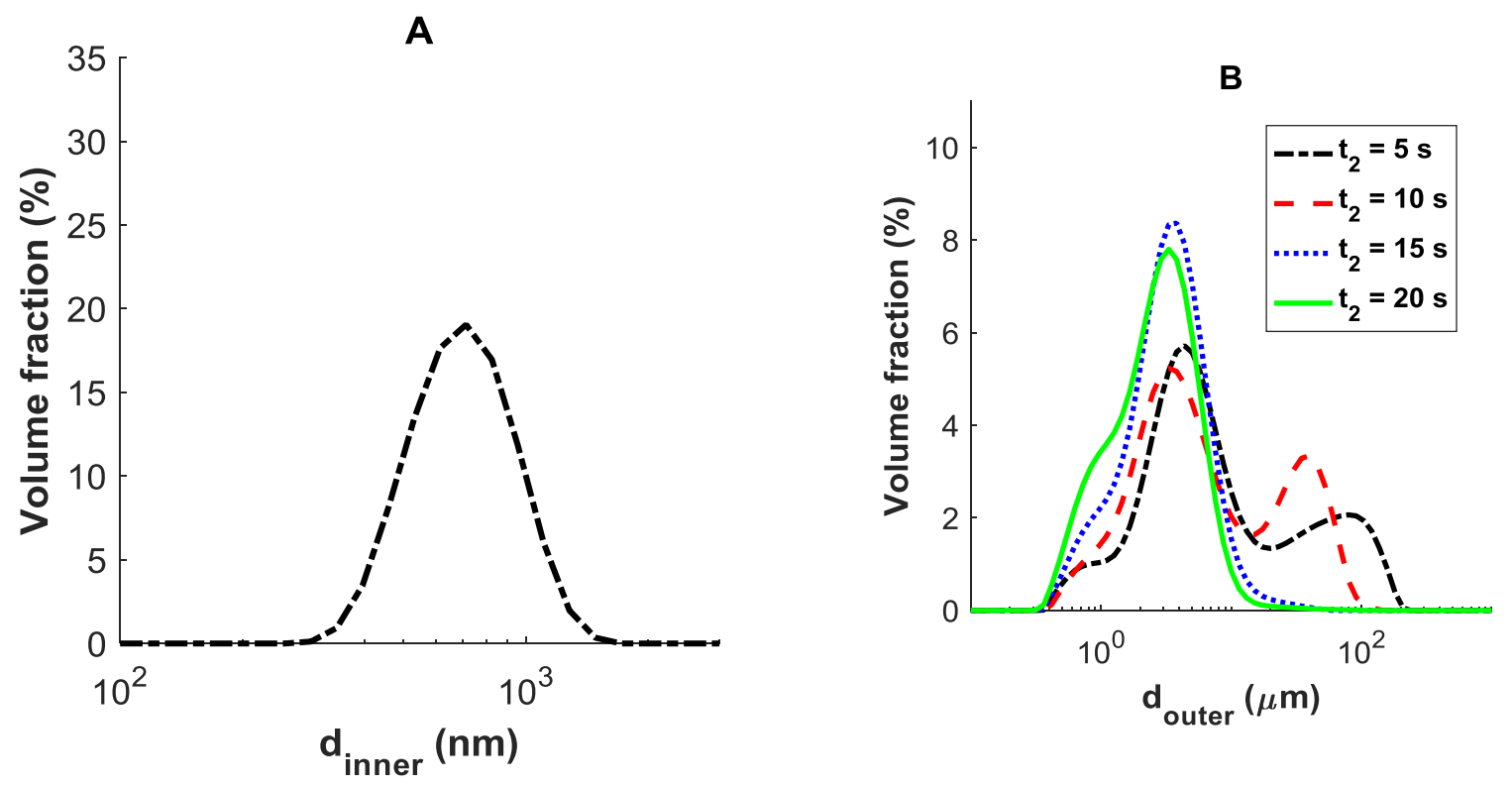


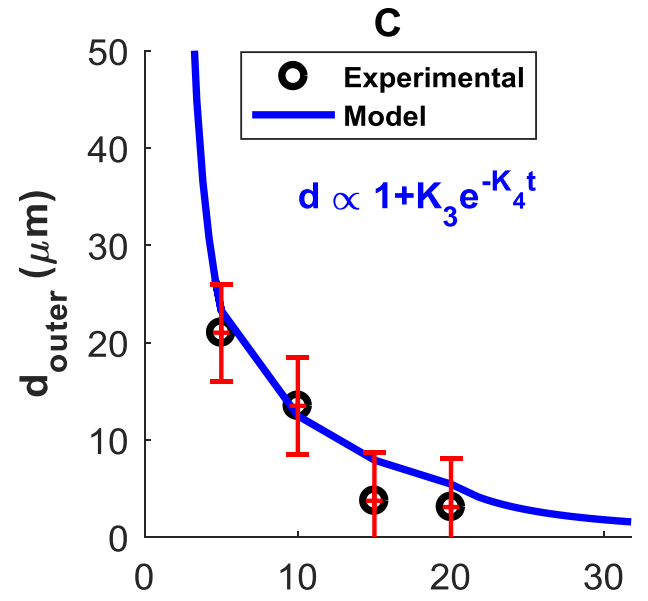

Second step sonication time (s)

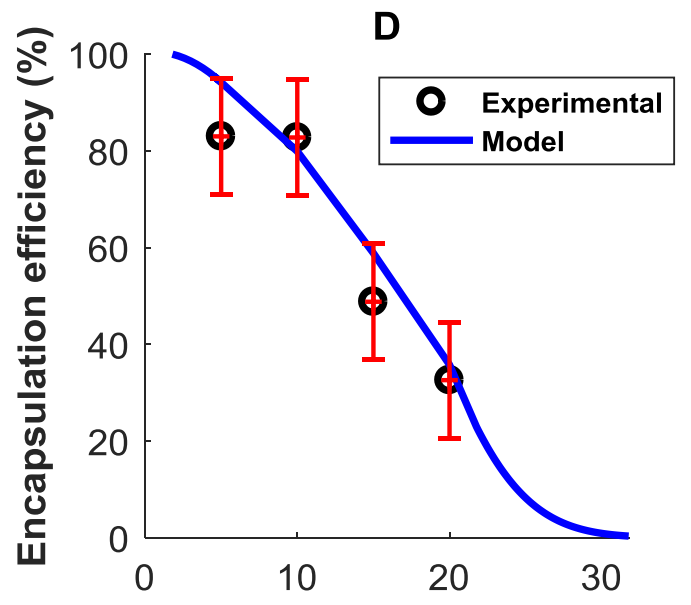

Second step sonication time (s)

Figure 1. Effect of the sonication time in the second emulsification step. (A) Size distribution of inner droplets, (B) size distribution of outer droplets, (C) mean diameter of outer droplets, and (D) encapsulation efficiency. The model curve is obtained by eq. 8 for the droplet diameter (giving similar results as eq. 9 here) and using equations 10-11 for the yield.

\subsection{Effect of the oil viscosity}

In order to investigate the effect of the oil phase viscosity, four paraffin oils with different

viscosities were used: $\mu_{\text {Macrol 52 }}=6, \mu_{\text {Macrol 82 }}=22, \mu_{\text {Fluid Paraffin oil }}=32$ and $\mu_{\text {Mineral oil }}=$ $45 \mathrm{mPa}$.s. As in the previous section, the primary emulsions were sonicated with $20 \%$ energy amplitude for $60 \mathrm{~s}(16 \mathrm{~W})$.

Figure 2A shows the size distribution of the inner droplets obtained with the different oil viscosities. While similar sonication energies and times were employed for all oils, bigger water inner droplets were produced when increasing the oil viscosity. These primary emulsions were then used to produce double emulsions by sonication at an energy amplitude of $20 \%$ for $10 \mathrm{~s}$ (11 W). Figure 2B shows the size distribution of the outer droplets of different oil viscosities. It can be seen that increasing the oil viscosity leads to the production of slightly bigger outer droplets, except the distribution obtained with the oil of $6 \mathrm{mPa} . \mathrm{s}$ which is wider. 
In order to explain these observations, the critical capillary is investigated for both the internal and external emulsions. For the primary emulsion, where water constitutes the dispersed phase and oil the continuous phase, the range of viscosity ratios $\left(\frac{\mu_{\mathrm{d}}}{\mu_{\mathrm{c}}}=\frac{\mu_{\mathrm{water}}}{\mu_{\mathrm{oil}}}\right)$ is $0.02,0.028,0.04$ and 0.15 (corresponding to oil viscosities of 45, 32, 22 and $6 \mathrm{mPa} . \mathrm{s}$ ), thus less than unity. Based on the Taylor theory ${ }^{50}$, the critical capillary decreases with $\frac{\mu_{\mathrm{d}}}{\mu_{\mathrm{c}}}$ when $\frac{\mu_{\mathrm{d}}}{\mu_{\mathrm{c}}}<1$. Therefore, the primary emulsions have bigger sizes when the oil viscosities are higher (i.e. lower viscosity ratios) (Figure 2A). For the external emulsions, the range of viscosity ratios is 6.7-55. The critical capillary starts to increase with $\frac{\mu_{\mathrm{d}}}{\mu_{\mathrm{c}}}$ when $\frac{\mu_{\mathrm{d}}}{\mu_{\mathrm{c}}}>7$. Therefore, the outer droplets move towards bigger sizes (Figure $2 \mathrm{~B}$ and $\mathrm{C}$ ), i.e., the turbulent disrupting force needs to overcome interfacial forces besides an increasing viscous force. With an oil viscosity of $6 \mathrm{mPa}$.s, the viscosity ratio is in the intermediate range, i.e. $1<\frac{\mu_{\mathrm{d}}}{\mu_{\mathrm{c}}}<7$, where a small effect of the viscosity ratio is observed on the size, and $\beta$ starts changing of sign. In other words, the factor $\beta$ in $\left(\frac{\mu_{\mathrm{d}}}{\mu_{\mathrm{c}}}\right)^{\beta}$, is negative for the inner droplet and positive for the outer droplets in this study. This allows to predict the droplet size over the whole region of $\frac{\mu_{\mathrm{d}}}{\mu_{\mathrm{c}}}$, considering updating the parameter $\beta$. Nazarzadeh and Sajjadi ${ }^{50}$, studied the effect of viscosity ratio between 0.4 and 100 on the size of emulsions prepared with ultrasound and observed a similar decrease, followed by an almost constant range, then an increase in the droplet size for $\frac{\mu_{\mathrm{d}}}{\mu_{\mathrm{c}}}<1,1<\frac{\mu_{\mathrm{d}}}{\mu_{\mathrm{c}}}<7$, and $\frac{\mu_{\mathrm{d}}}{\mu_{\mathrm{c}}}>7$ respectively. 

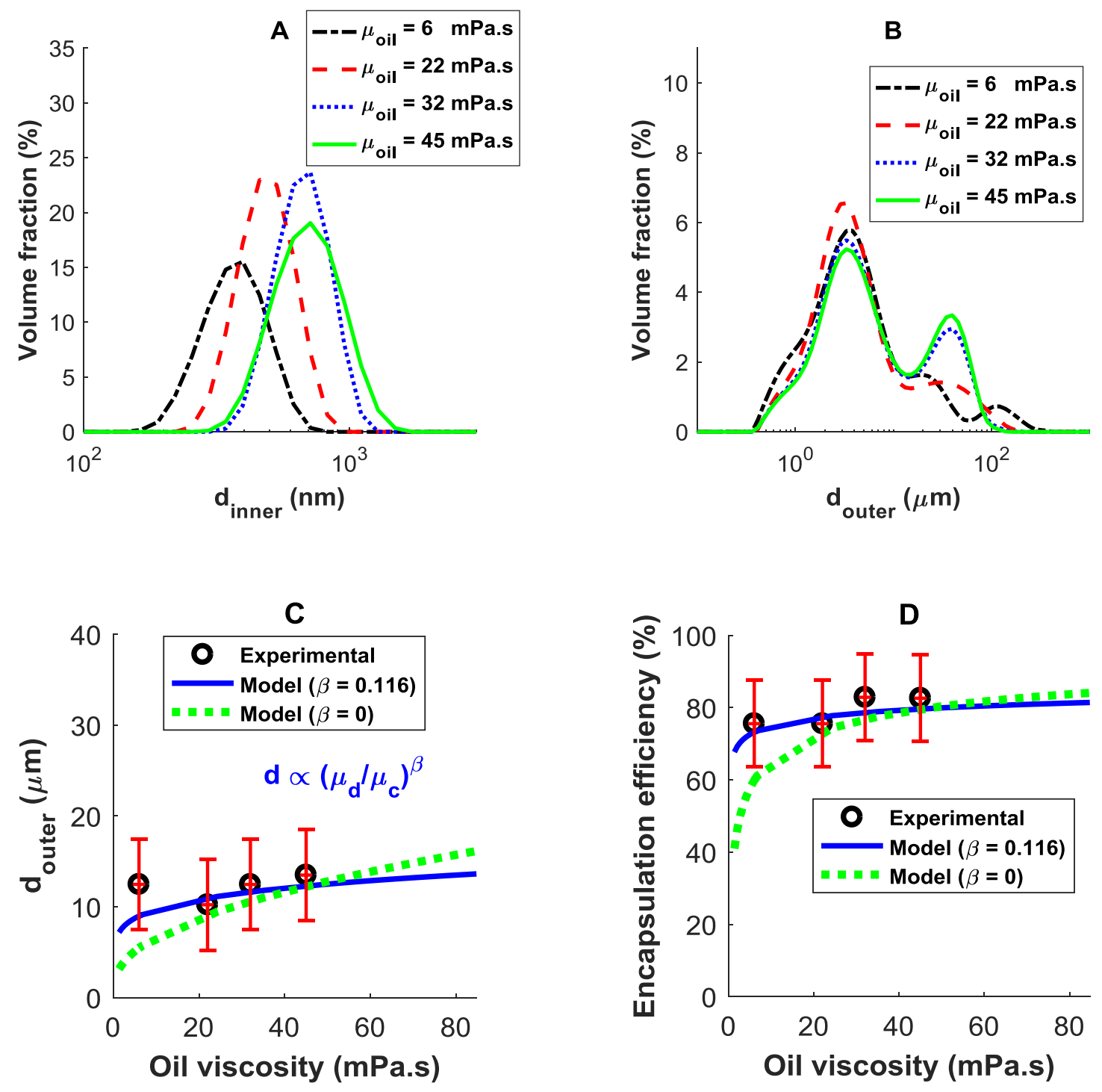

Figure 2. Effect of the oil viscosity. (A) Size distribution of inner droplets, (B) size distribution of outer droplets, (C) mean size of outer droplets, and (D) encapsulation efficiency. The estimated size is given by eq. 8 , both for $\beta=0$ (with $K_{1}=0.0053, K_{2}=0.0146$ ) and $\beta=0.116$ (with the parameters of Table 4), and the encapsulation efficiency is obtained by equations 10-11.

The model results for the outer droplet size and encapsulation efficiency are shown in figures $2 \mathrm{C}$ and $2 \mathrm{D}$ respectively. In order to demonstrate the interest of incorporating the viscosity ratio in the model, equation 8 is plotted with the optimized value of $\beta$ as well as with $\beta=0$, thus assuming $C$ to be constant in $C a_{\text {crit }}=C(1+f(O h))$, as done by Gupta model ${ }^{51}$. It can be seen 
that accounting for the viscosity ratio leads to a better agreement. However, a different values of $\beta$ would be required for oil viscosities lower than $6 \mathrm{mPa}$.s, as explained above.

\subsection{Effect of $\mathrm{NaCl}$ fraction}

The primary emulsions were sonicated during 60 s with $20 \%$ energy amplitude (16 W) using different $\mathrm{NaCl}$ fractions, $\phi_{\mathrm{NaCl}}: 0.025 \%, 0.05 \%, 0.1 \%$, and $0.15 \%$ (Set 3, Table 1). Figure 3A shows a slight increase in the size of the inner droplets when increasing the salt fraction, however the minimal size is obtained using $\phi_{\mathrm{NaCl}}=0.05 \%$. The presence of ions is known to have an effect on the adsorption of surfactant or its spreading on the interface, thus increasing the interfacial tension. This leads to a lower breakage rate, and so to the formation of bigger droplets. Kent and Saunders (2001) similarly indicated that the presence of salt generated higher interfacial tension that was justified by a possible delay in the absorption of surfactant at the oil-water interface ${ }^{83}$.

Double emulsions were then sonicated with an energy amplitude of $20 \%$ for $10 \mathrm{~s}(11 \mathrm{~W})$. The part of equations 8 and 9 that accounts for the effect of salt fraction is described by $\left(\sigma_{\mathrm{M}}+\right.$ $\left.K_{2} \phi_{\mu} C_{\text {salt }} R T d\right)$ or $\left(\sigma_{\mathrm{M}}+C_{2} \phi_{\mu} C_{\text {salt }} R T d\right)^{2 / 3}$ respectively. Accordingly, an increase in the outer droplet size is expected when increasing the salt fraction. Figures $3 B$ and $3 C$ indicate an increase in the outer droplet size and Figure 3D shows a higher encapsulation efficiency, when increasing the salt in the internal phase. The observed lower breakage rate when increasing the salt concentration is a consequence of the increased effective interfacial tension term that includes the osmotic pressure. It can be seen that the model allows describing accurately this phenomena. Indeed, using equation $7, \sigma_{\mathrm{M} \text {,eff }}$ is found to be equal to $0.008,0.009,0.013$, and 
$0.02 \mathrm{~N} . \mathrm{m}^{-1}$ for $\phi_{\mathrm{NaCl}} 0.025 \%, 0.05 \%, 0.1 \%$, and $0.15 \%$, respectively, while the measured $\sigma_{\mathrm{M}}$ is 0.007 N.m $\mathrm{m}^{-1}$

Note that while the two models predict similar mean diameters over the investigated range of salt fractions (up to $\phi_{\mathrm{NaCl}}=0.15 \%$ ), when extrapolating to higher salt fractions the models deviate from each other (figure $3 \mathrm{C}$ ). Usually the salt fraction is never so high, but if required, this region should be investigated experimentally to check which model would be more appropriate in regions with extremely high salt fractions.
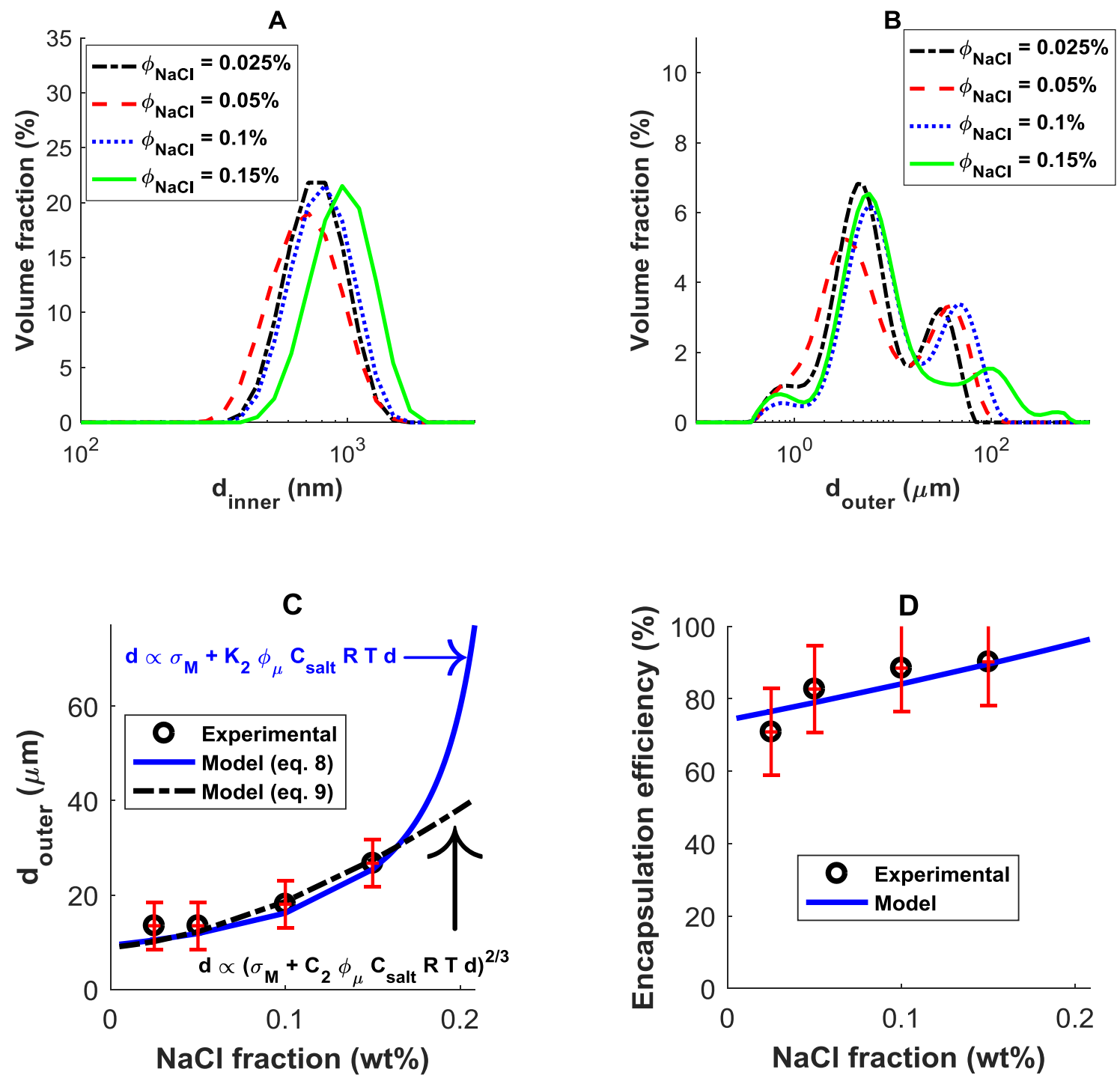
Figure 3. Effect of the $\mathrm{NaCl}$ fraction. (A) Size distribution of inner droplets, (B) size distribution of outer droplets, (C) mean size of outer droplets, and (D) encapsulation efficiency. The model curve is based on equations 8 and 9 for the droplet diameter and equations 10-11 for the yield.

\subsection{Effect of the primary emulsion fraction}

A primary emulsion was prepared as previously, with $60 \mathrm{~s}$ of sonication and $20 \%$ energy amplitude $(16 \mathrm{~W})$. The size distribution of the inner droplets is presented in Figure 4A. Then, the double emulsions were sonicated with an energy amplitude $20 \%$ (11 W) during 10 s using different fractions of the primary emulsion, $\phi_{\mathrm{M}}: 10 \%, 20 \%, 30 \%$ and $40 \%$.
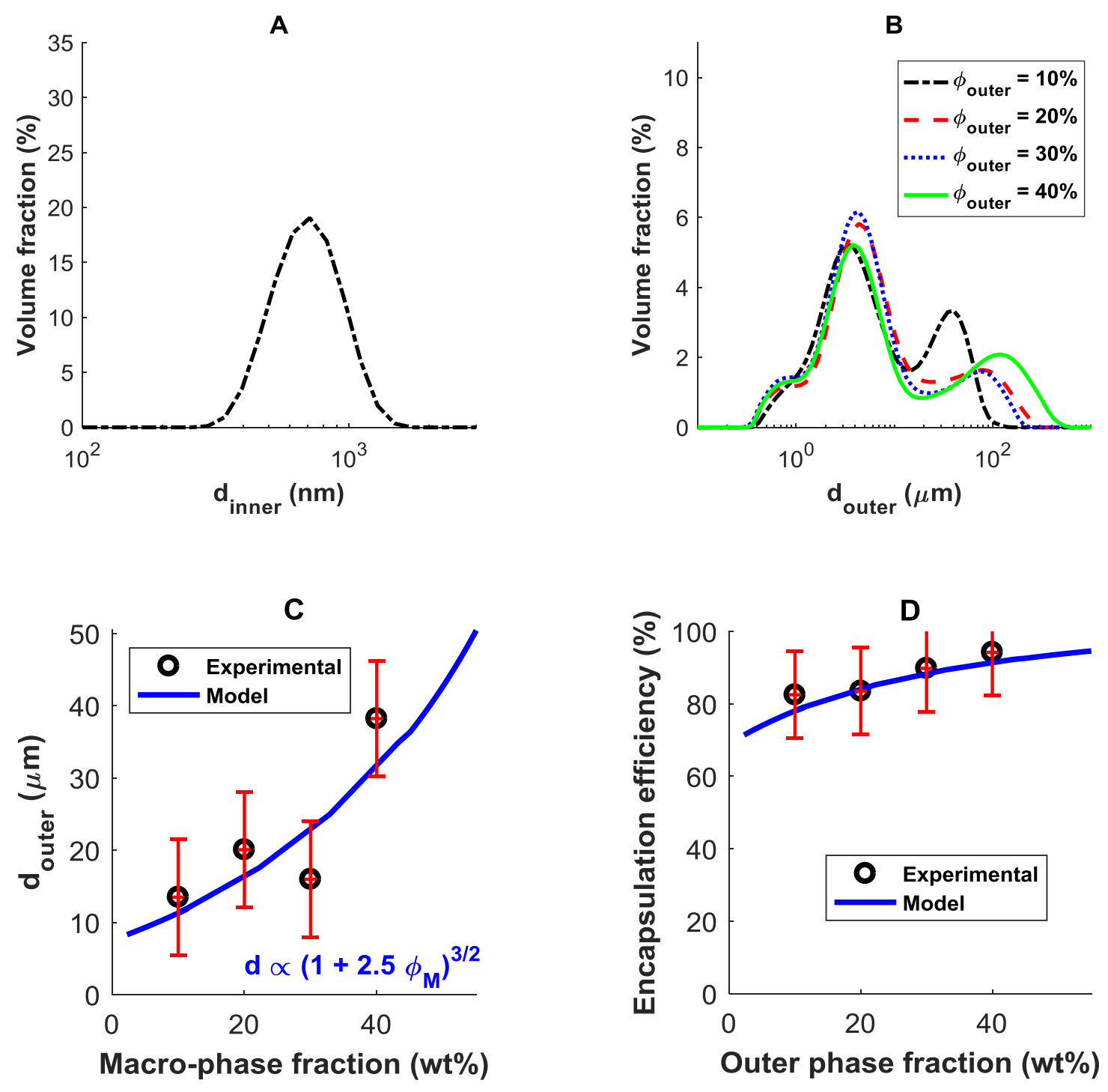
Figure 4. Effect of the primary emulsion fraction. (A) size distribution of inner droplets, (B) size distribution of outer droplets, (C) mean size of outer droplets, and (D) encapsulation efficiency. The model is based on equation 8 for the droplet diameter and equations 10-11 for the yield.

The terms accounting for the fraction of the dispersed phase in the droplet correction are given by $\left(1+2.5 \phi_{\mathrm{M}}\right)^{3 / 2}$ and $\left(1+2.5 \phi_{\mathrm{M}}\right)^{5 / 4}$ for equations 8 and 9 respectively. This term indicates a damping effect, where increasing $\phi_{\mathrm{M}}$ lowers the energy dissipation rate and thus hinders the breakage of outer droplet. Figures $4 \mathrm{~B}$ and $4 \mathrm{C}$ show respectively the size distribution of the outer droplets and their mean diameters as a function of the fraction of the primary emulsion. A general increase in the outer droplet size can be observed when increasing $\phi_{\mathrm{M}}$. This can be due to a decreased breakage rate (due to the energy dissipation damping) or to an enhanced coalescence rate (due to the higher collision frequency when increasing the dispersed phase fraction). However, Figure 4D indicates that the encapsulation efficiency increases slightly with $\phi_{\mathrm{M}}$, as observed by Leong et al. (2017) ${ }^{3}$. From these combined observations, it can be concluded that when increasing the fraction of the primary emulsion, the effective energy imposing on the surface of the outer droplets is damped, leading to a decrease in the breakage and so leakage. Indeed, outer droplet coalescence would not have a direct effect on the encapsulation efficiency and cannot explain both observations. As the model takes into account the damping effect for dissipation subrange, by an analogical derivation of the method of Doulah $^{61}$, it shows a good agreement with the experimental data. Leong et al. $(2017)^{3}$ did not observe an effect of $\phi_{\mathrm{M}}$ (varied up to $20 \%$ ) on the outer droplet size, except when employing extremely low calorimetric power of $2 \mathrm{~W}$ or extremely high power of $26 \mathrm{~W}$, where an increase in the outer droplet size was increasing with $\phi_{\mathrm{M}}$. 


\section{Conclusions}

The droplet size and encapsulation efficiency are key parameters of the final product properties of double emulsions. The effect of the process variables on these parameters were investigated experimentally and by modelling. Two correlations for the outer droplet mean diameter were proposed based on fundamental developments for the dissipation energy subrange and accounting for different properties, including the interfacial tension, the viscosities and densities of both phases, the fraction of salt and the sonication time and energy. A correlation is also proposed to estimate the leakage rate.

- Increasing the second step sonication time was found to create smaller outer droplets and consequently higher leakage, until reaching the equilibrium size. At equilibrium, the breakage rate is equal to the coalescence rate and therefore the size does not evolve but the inner droplet leakage continues at a constant rate.

- Increasing the oil viscosity of W/O/W double emulsions was found to form bigger inner droplets (where water represents the dispersed phase) and bigger outer droplets (where the water-oil dispersion represents the dispersed phase) and to lower the leakage rate. This could be explained by the capillary critical, $\left(\frac{\mu_{\mathrm{d}}}{\mu_{\mathrm{c}}}\right)^{\beta}$, where $\beta$ is negative for the inner droplets and positive for the outer droplets.

- Increasing the salt fraction was found to hinder the breakage, and leakage, and thus to form bigger outer droplets. This phenomenon is driven by the osmotic pressure that adds a force to the droplets interface. 
- Increasing the fraction of the primary emulsion was found to dampen the effective energy dissipation rate and thus to form bigger outer droplets and less leakage.

As a perspective, there is still a need to account for the inner droplet size and fraction in the breakage rate, for instance through the outer droplets viscosity and cohesion forces. Moreover, it would be interesting to implement a population balance model to predict the evolution of the droplet size distribution with time.

\section{Acknowledgement}

This work was funded by ModLife ITN. Grant agreement number 675251.

The authors would like to show their gratitude to Professor Guoping Lian (UNILEVER, UK) and Dr. Stéphane Labouret (University of Lyon, FRANCE) for their advises in this work.

\section{References}

(1) Seifriz, W. Studies in Emulsions. I-II. J. Phys. Chem. 1924, 29 (5), 587-600. https://doi.org/10.1021/j150251a008.

(2) Muschiolik, G. Multiple Emulsions for Food Use. Curr. Opin. Colloid Interface Sci. 2007, 12 (4-5), 213-220. https://doi.org/10.1016/j.cocis.2007.07.006.

(3) Leong, T. S. H.; Zhou, M.; Kukan, N.; Ashokkumar, M.; Martin, G. J. O. Preparation of Water-in-Oil-in-Water Emulsions by Low Frequency Ultrasound Using Skim Milk and Sunflower Oil. Food Hydrocoll. 2017, 63, 685-695. https://doi.org/10.1016/j.foodhyd.2016.10.017.

(4) Multiple Emulsions: Technology and Applications; Aserin, A., Ed.; Wiley series on surface and interfacial chemistry; Wiley-Interscience: Hoboken, N.J, 2008.

(5) Florence, A. T.; Whitehill, D. The Formulation and Stability of Multiple Emulsions. Int. J. Pharm. 1982, 11 (4), 277-308.

(6) Khurana, J.; Singh, S.; Dash, A. Multiple Emulsions: An Overview and Pharmaceutical Applications. In Colloids in Drug Delivery; Fanun, M., Ed.; CRC Press, 2010; Vol. 20100581, pp 177-202. https://doi.org/10.1201/9781439818268-c7.

(7) Membrane Handbook; Ho, W. S. W., Sirkar, K. K., Eds.; Springer US: Boston, MA, 1992. https://doi.org/10.1007/978-1-4615-3548-5. 
(8) Takht Ravanchi, M.; Kaghazchi, T.; Kargari, A. Application of Membrane Separation Processes in Petrochemical Industry: A Review. Desalination 2009, 235 (1-3), 199-244. https://doi.org/10.1016/j.desal.2007.10.042.

(9) Schmidts, T.; Dobler, D.; Nissing, C.; Runkel, F. Influence of Hydrophilic Surfactants on the Properties of Multiple W/O/W Emulsions. J. Colloid Interface Sci. 2009, 338 (1), 184-192. https://doi.org/10.1016/j.jcis.2009.06.033.

(10) Matsumoto, S.; Kita, Y.; Yonezawa, D. An Attempt at Preparing Water-in-Oil-in-Water Multiple-Phase Emulsions. J. Colloid Interface Sci. 1976, 57 (2), 353-361. https://doi.org/10.1016/0021-9797(76)90210-1.

(11) Lindenstruth, K.; Müller, B. W. W/O/W Multiple Emulsions with Diclofenac Sodium. Eur. J. Pharm. Biopharm. 2004, 58 (3), 621-627. https://doi.org/10.1016/j.ejpb.2004.04.003.

(12) Chávez-Páez, M.; Quezada, C. M.; Ibarra-Bracamontes, L.; González-Ochoa, H. O.; ArauzLara, J. L. Coalescence in Double Emulsions. Langmuir 2012, 28 (14), 5934-5939. https://doi.org/10.1021/la205144g.

(13) Jager-Lezer, N.; Terrisse, I.; Bruneau, F.; Tokgoz, S.; Ferreira, L.; Clausse, D.; Seiller, M.; Grossiord, J.-L. Influence of Lipophilic Surfactant on the Release Kinetics of Water-Soluble Molecules Entrapped in a W/O/W Multiple Emulsion. J. Controlled Release 1997, 45 (1), 1-13. https://doi.org/10.1016/S0168-3659(96)01507-6.

(14) Mezzenga, R.; Folmer, B. M.; Hughes, E. Design of Double Emulsions by Osmotic Pressure Tailoring. Langmuir 2004, 20 (9), 3574-3582. https://doi.org/10.1021/la036396k.

(15) Shere, A. J.; Cheung, H. M. MODELING OF LEAKAGE IN LIQUID SURFACTANT MEMBRANE SYSTEMS. Chem. Eng. Commun. 1988, 68 (1), 143-164. https://doi.org/10.1080/00986448808940403.

(16) Schuch, A.; Wrenger, J.; Schuchmann, H. P. Production of W/O/W Double Emulsions. Part II: Influence of Emulsification Device on Release of Water by Coalescence. Colloids Surf. Physicochem. Eng. Asp. 2014, 461, 344-351. https://doi.org/10.1016/j.colsurfa.2013.11.044.

(17) Leong, T. S. H.; Martin, G. J. O.; Ashokkumar, M. Ultrasonic Encapsulation - A Review. Ultrason. Sonochem. 2017, 35, 605-614. https://doi.org/10.1016/j.ultsonch.2016.03.017.

(18) Lamba, H.; Sathish, K.; Sabikhi, L. Double Emulsions: Emerging Delivery System for Plant Bioactives. Food Bioprocess Technol. 2015, 8 (4), 709-728. https://doi.org/10.1007/s11947-014-1468-6.

(19) Leong, T. S. H.; Wooster, T. J.; Kentish, S. E.; Ashokkumar, M. Minimising Oil Droplet Size Using Ultrasonic Emulsification. Ultrason. Sonochem. 2009, 16 (6), 721-727. https://doi.org/10.1016/j.ultsonch.2009.02.008.

(20) Leong, T. S. H.; Manickam, S.; Martin, G. J. O.; Li, W.; Ashokkumar, M. Ultrasonic Production of Nano-Emulsions for Bioactive Delivery in Drug and Food Applications; SpringerBriefs in Molecular Science; Springer International Publishing: Cham, 2018. https://doi.org/10.1007/978-3-319-73491-0.

(21) Mahdi Jafari, S.; He, Y.; Bhandari, B. Nano-Emulsion Production by Sonication and Microfluidization-A Comparison. Int. J. Food Prop. 2006, 9 (3), 475-485. https://doi.org/10.1080/10942910600596464. 
(22) Li, M. K.; Fogler, H. S. Acoustic Emulsification. Part 1. The Instability of the Oil-Water Interface to Form the Initial Droplets. J. Fluid Mech. 1978, 88 (03), 499. https://doi.org/10.1017/S0022112078002232.

(23) Li, M. K.; Fogler, H. S. Acoustic Emulsification. Part 2. Breakup of the Large Primary Oil Droplets in a Water Medium. J. Fluid Mech. 1978, 88 (03), 513. https://doi.org/10.1017/S0022112078002244.

(24) Shanmugam, A.; Ashokkumar, M. Ultrasonic Preparation of Food Emulsions. In Ultrasound in Food Processing; Villamiel, M., Montilla, A., García-Pérez, J. V., Cárcel, J. A., Benedito, J., Eds.; John Wiley \& Sons, Ltd: Chichester, UK, 2017; pp 287-310. https://doi.org/10.1002/9781118964156.ch10.

(25) Leong, T.; Ashokkumar, M.; Kentish, S. The Fundamentals of Power Ultrasound-A Review. 2011.

(26) Tornberg, E.; Hermansson, A.-M. FUNCTIONAL CHARACTERIZATION OF PROTEIN STABILIZED EMULSIONS: EFFECT OF PROCESSING. J. Food Sci. 1977, 42 (2), 468-472. https://doi.org/10.1111/j.1365-2621.1977.tb01524.x.

(27) Kentish, S.; Wooster, T. J.; Ashokkumar, M.; Balachandran, S.; Mawson, R.; Simons, L. The Use of Ultrasonics for Nanoemulsion Preparation. Innov. Food Sci. Emerg. Technol. 2008, 9 (2), 170-175. https://doi.org/10.1016/j.ifset.2007.07.005.

(28) Gaikwad, S. G.; Pandit, A. B. Ultrasound Emulsification: Effect of Ultrasonic and Physicochemical Properties on Dispersed Phase Volume and Droplet Size. Ultrason. Sonochem. 2008, 15 (4), 554-563. https://doi.org/10.1016/j.ultsonch.2007.06.011.

(29) Rajian, J. R.; Fabiilli, M. L.; Fowlkes, J. B.; Carson, P. L.; Wang, X. Drug Delivery Monitoring by Photoacoustic Tomography with an ICG Encapsulated Double Emulsion. Opt. Express 2011, 19 (15), 14335. https://doi.org/10.1364/OE.19.014335.

(30) Kim, C.-K.; Kim, S.-C.; Shin, H.-J.; Kim, K. M.; Oh, K.-H.; Lee, Y.-B.; Oh, I.-J. Preparation and Characterization of Cytarabine-Loaded w/o/w Multiple Emulsions. Int. J. Pharm. 1995, 124 (1), 61-67. https://doi.org/10.1016/0378-5173(95)00074-S.

(31) Aditya, N. P.; Aditya, S.; Yang, H.; Kim, H. W.; Park, S. O.; Ko, S. Co-Delivery of Hydrophobic Curcumin and Hydrophilic Catechin by a Water-in-Oil-in-Water Double Emulsion. Food Chem. 2015, 173, 7-13. https://doi.org/10.1016/j.foodchem.2014.09.131.

(32) Zeng, L.; Zhang, Y.; Bukirwa, C.; Li, W.; Yang, Y. Study of Mean Diameter and Drop Size Distribution of Emulsion Drops in a Modified Rotating Disc Contactor for an Emulsion Liquid Membrane System. RSC Adv. 2015, 5 (109), 89959-89970. https://doi.org/10.1039/C5RA16267J.

(33) Davis, S. S.; Burbage, A. S. The Particle Size Analysis of Multiple Emulsions (Water-in-Oilin-Water). In Particle Size Analysis; Heyden \& Son: University of Salford, 1977; Vol. 2, p 395.

(34) Tang, S. Y.; Sivakumar, M. Design and Evaluation of Aspirin-Loaded Water-in-Oil-in-Water Submicron Multiple Emulsions Generated Using Two-Stage Ultrasonic Cavitational Emulsification Technique: SUBMICRON W/O/W MULTIPLE EMULSIONS OF ASPIRIN BY ULTRASONIC CAVITATION. Asia-Pac. J. Chem. Eng. 2012, 7, S145-S156. https://doi.org/10.1002/apj.664. 
(35) Tang, S. Y.; Sivakumar, M.; Nashiru, B. Impact of Osmotic Pressure and Gelling in the Generation of Highly Stable Single Core Water-in-Oil-in-Water (W/O/W) Nano Multiple Emulsions of Aspirin Assisted by Two-Stage Ultrasonic Cavitational Emulsification. Colloids Surf. B Biointerfaces 2013, 102, 653-658. https://doi.org/10.1016/j.colsurfb.2012.08.036.

(36) Tal-Figiel, B. The Formation of Stable W/O, O/W, W/O/W Cosmetic Emulsions in an Ultrasonic Field. Chem. Eng. Res. Des. 2007, 85 (5), 730-734. https://doi.org/10.1205/cherd06199.

(37) Ghasemi, H.; Mazloomi, H.; Hajipour, H. Stabilization of Multiple Emulsions Using Natural Surfactants. ArXiv170508296 Cond-Mat 2017.

(38) Leong, T. S. H.; Zhou, M.; Zhou, D.; Ashokkumar, M.; Martin, G. J. O. The Formation of Double Emulsions in Skim Milk Using Minimal Food-Grade Emulsifiers - A Comparison between Ultrasonic and High Pressure Homogenisation Efficiencies. J. Food Eng. 2018, 219, 81-92. https://doi.org/10.1016/j.jfoodeng.2017.09.018.

(39) Okazaki, S.; Imai, M.; Shimizu, M. Leakage Suppressing Oe W/O Emulsion Using High Viscous Solvent. In Process Metallurgy; Elsevier, 1992; Vol. 7, pp 1487-1492. https://doi.org/10.1016/B978-0-444-88677-4.50064-7.

(40) Hinze, J. O. Fundamentals of the Hydrodynamic Mechanism of Splitting in Dispersion Processes. AIChE J. 1955, 1 (3), 289-295. https://doi.org/10.1002/aic.690010303.

(41) Brinkman, H. C. Brownian Motion in a Field of Force and the Diffusion Theory of Chemical Reactions. Physica 1956, 22 (1-5), 29-34. https://doi.org/10.1016/S00318914(56)80006-2.

(42) Mlynek, Y.; Resnick, W. Drop Sizes in an Agitated Liquid-Liquid System. AIChE J. 1972, 18 (1), 122-127. https://doi.org/10.1002/aic.690180122.

(43) Coulaloglou, C. A.; Tavlarides, L. L. Drop Size Distributions and Coalescence Frequencies of Liquid-Liquid Dispersions in Flow Vessels. AlChE J. 1976, 22 (2), 289-297. https://doi.org/10.1002/aic.690220211.

(44) Kataoka, T.; Nishiki, T. Dispersed Mean Drop Sizes of (W/O)/W Emulsions in a Stirred Tank. J. Chem. Eng. Jpn. 1986, 19 (5), 408-412. https://doi.org/10.1252/jcej.19.408.

(45) Ohtake, T.; Hano, T.; Takagi, K.; Nakashio, F. Effects of Viscosity on Drop Diameter of W/O Emulsion Dispersed in a Stirred Tank. J. Chem. Eng. Jpn. 1987, 20 (5), 443-447. https://doi.org/10.1252/jcej.20.443.

(46) Rautenbach, R.; Machhammer, O. Modeling of Liquid Membrane Separation Processes. J. Membr. Sci. 1988, 36, 425-444. https://doi.org/10.1016/0376-7388(88)80034-6.

(47) Gallego-Lizon, T.; Pérez de Ortiz, E. S. Drop Sizes in Liquid Membrane Dispersions. Ind. Eng. Chem. Res. 2000, 39 (12), 5020-5028. https://doi.org/10.1021/ie000016y.

(48) Karbstein, H.; Schubert, H. Developments in the Continuous Mechanical Production of Oil-in-Water Macro-Emulsions. Chem. Eng. Process. Process Intensif. 1995, 34 (3), 205211. https://doi.org/10.1016/0255-2701(94)04005-2.

(49) O'Sullivan, J.; Murray, B.; Flynn, C.; Norton, I. Comparison of Batch and Continuous Ultrasonic Emulsification Processes. J. Food Eng. 2015, 167, 114-121. https://doi.org/10.1016/j.jfoodeng.2015.05.001.

(50) Nazarzadeh, E.; Sajjadi, S. Viscosity Effects in Miniemulsification via Ultrasound. AlChE J. 2010, 56 (10), 2751-2755. https://doi.org/10.1002/aic.12133. 
(51) Gupta, A.; Eral, H. B.; Hatton, T. A.; Doyle, P. S. Controlling and Predicting Droplet Size of Nanoemulsions: Scaling Relations with Experimental Validation. Soft Matter 2016, 12 (5), 1452-1458. https://doi.org/10.1039/C5SM02051D.

(52) Kimura, T.; Sakamoto, T.; Leveque, J.-M.; Sohmiya, H.; Fujita, M.; Ikeda, S.; Ando, T. Standardization of Ultrasonic Power for Sonochemical Reaction. Ultrason. Sonochem. 1996, 3 (3), S157-S161.

(53) Schmidts, T.; Dobler, D.; Guldan, A.-C.; Paulus, N.; Runkel, F. Multiple W/O/W Emulsions-Using the Required HLB for Emulsifier Evaluation. Colloids Surf. Physicochem. Eng. Asp. 2010, 372 (1-3), 48-54. https://doi.org/10.1016/j.colsurfa.2010.09.025.

(54) Zhao, S.; Dong, Z.; Yao, C.; Wen, Z.; Chen, G.; Yuan, Q. Liquid-Liquid Two-Phase Flow in Ultrasonic Microreactors: Cavitation, Emulsification, and Mass Transfer Enhancement. AIChE J. 2018, 64 (4), 1412-1423. https://doi.org/10.1002/aic.16010.

(55) Kolmogorov, A. N. The Local Structure of Turbulence in Incompressible Viscous Fluid for Very Large Reynolds Numbers. In Dokl. Akad. Nauk SSSR; 1941; Vol. 30, pp 299-303.

(56) Fox, R. O. Computational Models for Turbulent Reacting Flows; Cambridge University Press: Cambridge, 2003. https://doi.org/10.1017/CBO9780511610103.

(57) Pope, S. B. Turbulent Flows; Cambridge University Press: Cambridge, 2000. https://doi.org/10.1017/CBO9780511840531.

(58) Karimi, M.; Andersson, R. An Exploratory Study on Fluid Particles Breakup Rate Models for the Entire Spectrum of Turbulent Energy. Chem. Eng. Sci. 2018, 192, 850-863. https://doi.org/10.1016/j.ces.2018.08.016.

(59) Sharma, A.; Goswami, A. N.; Rawat, B. S. Drop Size Prediction in Liquid Membrane Systems. J. Membr. Sci. 1991, 60 (2-3), 261-274. https://doi.org/10.1016/S03767388(00)81539-2.

(60) Andrey Kolmogorov. On the Breakage of Drops in a Turbulent Flow. Dokl Akad Navk SSSR 1949, 66.

(61) Doulah, M. S. An Effect of Hold-up on Drop Sizes in Liquid-Liquid Dispersions. Ind. Eng. Chem. Fundam. 1975, 14 (2), 137-138. https://doi.org/10.1021/i160054a015.

(62) DR. BROWN; K. Pitt. Drop Break-up in a Stirred Liquid-Liquid Contactor. BRITISH CHEMICAL ENGINEERING 1971, 16 (6), 525.

(63) CALDERBANK, P. H. Physical Rate Processes in Industrial Fermentations Part I: The Interfacial Area in Gas-Liquid Contacting with Mechanical Agitation. Trans Inst Chem Engrs 1958, 36, 443-463.

(64) Davies, J. T. Drop Sizes of Emulsions Related to Turbulent Energy Dissipation Rates. Chem. Eng. Sci. 1985, 40 (5), 839-842. https://doi.org/10.1016/0009-2509(85)85036-3.

(65) S. J. Chen; D. R. Libby. Gas-Liquid and Liquid-Liquid Dispersions in a Kenics Mixer; 1978.

(66) Taylor, G. I. The Viscosity of a Fluid Containing Small Drops of Another Fluid. Proc. R. Soc. Math. Phys. Eng. Sci. 1932, 138 (834), 41-48. https://doi.org/10.1098/rspa.1932.0169.

(67) Taylor, G. I. The Formation of Emulsions in Definable Fields of Flow. Proc. R. Soc. Math. Phys. Eng. Sci. 1934, 146 (858), 501-523. https://doi.org/10.1098/rspa.1934.0169.

(68) Shinnar, R. On the Behaviour of Liquid Dispersions in Mixing Vessels. J. Fluid Mech. 1961, 10 (02), 259. https://doi.org/10.1017/S0022112061000214. 
(69) Janssen, J. M. H.; Meijer, H. E. H. Droplet Breakup Mechanisms: Stepwise Equilibrium versus Transient Dispersion. J. Rheol. 1993, 37 (4), 597-608. https://doi.org/10.1122/1.550385.

(70) Taylor, G. I. Conical free surfaces and fluid interfaces. In Applied Mechanics; Görtler, H., Ed.; Springer Berlin Heidelberg: Berlin, Heidelberg, 1966; pp 790-796. https://doi.org/10.1007/978-3-662-29364-5_104.

(71) Hinch, E. J.; Acrivos, A. Long Slender Drops in a Simple Shear Flow. J. Fluid Mech. 1980, 98 (02), 305. https://doi.org/10.1017/S0022112080000171.

(72) Rallison, J. M. A Numerical Study of the Deformation and Burst of a Viscous Drop in General Shear Flows. J. Fluid Mech. 1981, 109 (1), 465. https://doi.org/10.1017/S002211208100116X.

(73) Bentley, B. J.; Leal, L. G. An Experimental Investigation of Drop Deformation and Breakup in Steady, Two-Dimensional Linear Flows. J. Fluid Mech. 1986, 167 (1), 241. https://doi.org/10.1017/S0022112086002811.

(74) Koglin, B.; Pawlowski, J.; Schnöring, H. Kontinuierliches Emulgieren Mit Rotor/StatorMaschinen: Einfluß Der Volumenbezogenen Dispergierleistung Und Der Verweilzeit Auf Die Emulsionsfeinheit: Kontinuierliches Emulgieren Mit Rotor/Stator-Maschinen: Einfluß Der Volumenbezogenen Dispergierleistung Und Der Verweilzeit Auf Die Emulsionsfeinheit. Chem. Ing. Tech. 1981, 53 (8), 641-647. https://doi.org/10.1002/cite.330530813.

(75) Theodore Vermeulen. Interfacial Area in Liquid-Liquid and Gas-Liquid Agitation. Chem. Eng. Progr. 1955, 51, 85F-94F.

(76) S.A. Miller; C.A. Mann. Agitation of Two-Phase Systems of Immiscible Liquids. Trans. Am. Inst. Chem. Engrs 1944, No. 40, 709-743.

(77) Michaut, F.; Perrin, P.; Hébraud, P. Interface Composition of Multiple Emulsions: Rheology as a Probe. Langmuir 2004, 20 (20), 8576-8581. https://doi.org/10.1021/la048715t.

(78) Spiegler, K. S.; Kedem, O. Thermodynamics of Hyperfiltration (Reverse Osmosis): Criteria for Efficient Membranes. Desalination 1966, 1 (4), 311-326. https://doi.org/10.1016/S0011-9164(00)80018-1.

(79) Voinova, M. V. The Theory of Membrane "Vitrification." Thermochim. Acta 1996, 280281, 465-477. https://doi.org/10.1016/0040-6031(95)02657-6.

(80) Sprow, F. B. Distribution of Drop Sizes Produced in Turbulent Liquid-Liquid Dispersion. Chem. Eng. Sci. 1967, 22 (3), 435-442. https://doi.org/10.1016/0009-2509(67)80130-1.

(81) Farzi, G. A.; Rezazadeh, N.; Nejad, A. P. Droplet Formation Study in Emulsification Process by KSM Using a Novel In Situ Visualization System. J. Dispers. Sci. Technol. 2016, 37 (4), 575-581. https://doi.org/10.1080/01932691.2015.1052144.

(82) Stanciu, I. A New Viscosity-Temperature Relationship for Mineral Oil SAE 10W. Analele Univ. Ovidius Constanta - Ser. Chim. 2012, 23 (1), 27-30. https://doi.org/10.2478/v10310-012-0003-8.

(83) Kent, P.; Saunders, B. R. The Role of Added Electrolyte in the Stabilization of Inverse Emulsions. J. Colloid Interface Sci. 2001, 242 (2), 437-442. https://doi.org/10.1006/jcis.2001.7792. 


\section{Graphical Abstract}

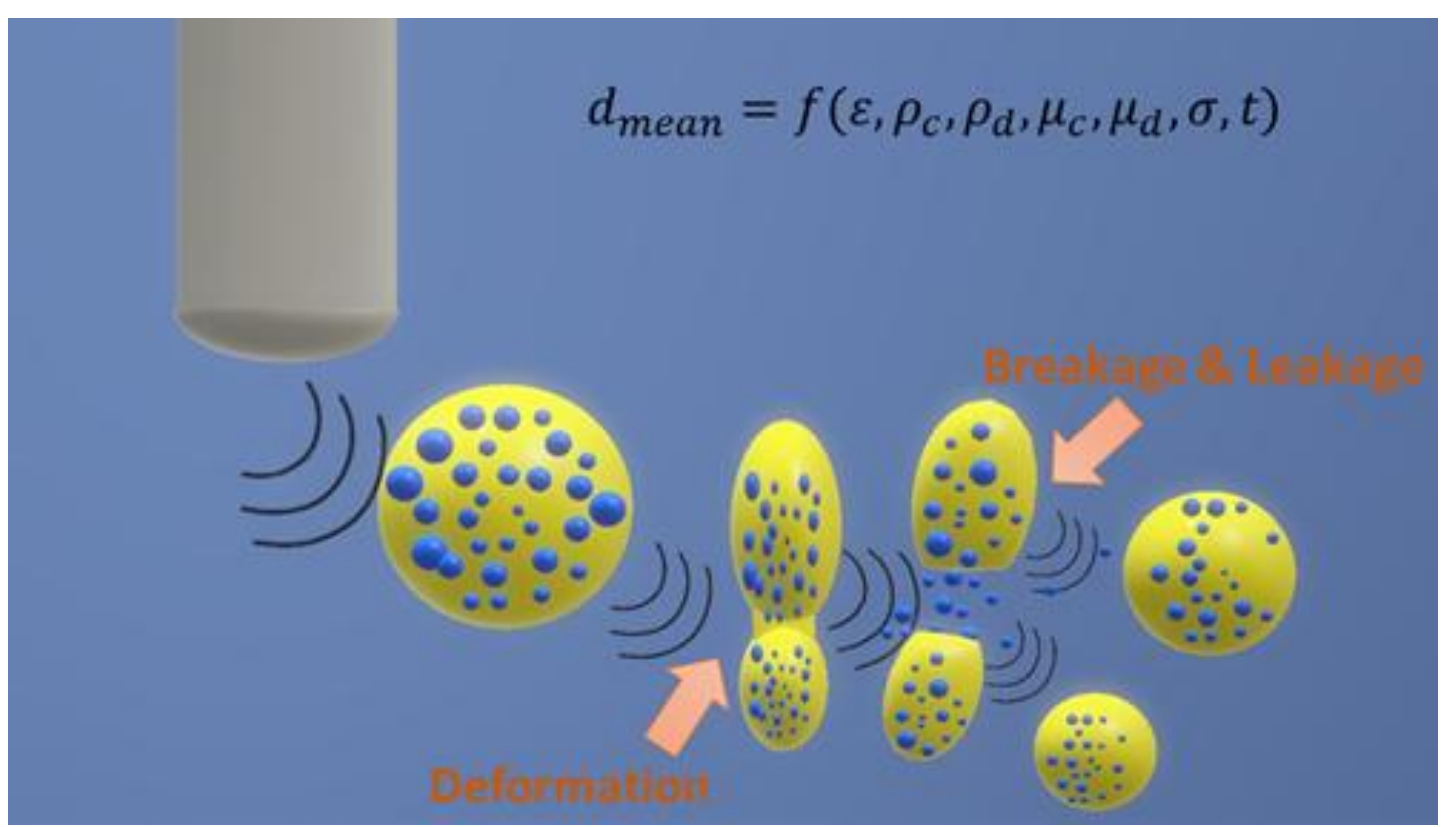

